\title{
Merging sustainability costs and benefits with government plans and budgets
}

\author{
K. McGovern ${ }^{1}$, L. Drennan ${ }^{2}$ \& E. Meier ${ }^{3}$ \\ ${ }^{1} K$ McGovern \& Associates, Australia \\ ${ }^{2}$ Queensland University of Technology, Australia \\ ${ }^{3}$ Queensland Department of Natural Resources and Water, Australia
}

\begin{abstract}
"It has become apparent that planners, environmentalists, architects, engineers, policy makers and economists have to work together in order to ensure that development can meet our present needs without compromising the ability of future generations." (WIT Sustainable Development Conference 2007)

How do economists and policy makers merge environmental costs and benefits with whole-of-government plans and budgets? Scientists must collaborate with industry, the community and government to create support for achieving environmental outcomes. To achieve specific environmental outcomes, government support is needed. To gain government's support, scientists should provide specific, measurable and fully costed proposals that, when implemented, result in the desired outcome. Stakeholders recognise that a Government's budget is a political and financial instrument. Costs can only be recognised by government bodies once they have been included in the annual budget papers, or the budgets of government corporations and statutory bodies.

This paper discusses the processes necessary to gain government support and funding for policy initiatives. It reports on progress in sustainability reporting, proposes public sector agencies report the environmental costs and benefits and establishes a framework that merges sustainability reporting with the whole-of-government budgeting and reporting structures that are associated with government accountability.
\end{abstract}

Keywords: whole-of-government framework, sustainability reporting. 


\section{Introduction}

There is a "disconnect" between the interests of longer-term science outcomes and annual budget cycles that are only now beginning to be addressed through public sector agency sustainability reporting (also called triple bottom line reports, sustainable development reports or corporate responsibility reporting). Sustainability reports are being prepared within a common reporting framework that "incorporates goals and objectives set at a broader international level into the consideration of internal management processes" (GRI [2]:22). But how can these often long-term outcomes to be developed and integrated into short-term policy decision-making?

One role of government is to provide policy-certainty to the private sector. This paper discusses the processes necessary to gain government support for policy initiatives and funding. It reports on progress in reporting sustainability costs and benefits, proposes public sector agencies prepare sustainability reports, and establishes a framework that merges sustainability reporting in whole-ofgovernment plans and budgets and hence into the reporting structures associated with government accountability.

\section{Collaborating with government}

To collaborate effectively with government, scientists need to know the imperatives within which government operates. Scientists need to do more than produce "good science" and hope for their findings to be adopted intelligently. They need to understand the budget cycle that provides government its legitimacy, the Medium Term frameworks that record the future costs of current policies, and how to estimate the full costs (to the community, industry and government) of applying scientific findings.

\subsection{The role of scientists}

While it is desirable that government policy be based on "good science", Kummis reminds us that it is a myth that "good science can, by itself, somehow make difficult natural resource decisions for us and relieve us of the necessity to engage in the hard work of democratic deliberations that must finally shoulder the weight of those decisions" (Kemmis [2]). Scientists recognise their responsibility to communicate their research findings to the public, and "to increase dialogue on the social and ethical implications" thereof (MORI [3]:4). Once an invention or process has attained scientific credibility and can be shown to achieve sustainability outcomes, the scientist's role includes collaborating with communities (both individuals and local government), industry (both individual companies and industry bodies) and government (both agencies and the executive) to find practical ways of adopting the new invention or process. This collaboration can extend to the achievement of environmental outcomes, e.g. clean air resulting from the reduction of $\mathrm{CO} 2$ emissions by $4-7 \%$ (van Vuuren [4]). 
It is the role of the community, industry bodies and scientific institutions to lobby the government to achieve environmental outcomes. It is the contribution of the community, industry and scientific institutions to achieving environmental outcomes that attracts political support. To earn the respect of industry and community bodies, scientists need to move beyond pure science to applied science and demonstrate the link between their science and desired outcomes. In working collaboratively (Kemmis [2]), scientists learn to articulate clearly in layman's language the link between the desired behaviour and the resulting benefits. For example, they are able to demonstrate that coal stack scrubbers will improve the health of staff and that of people in adjacent communities; reduce the health department's future expenditure as well as the recurrent operating costs of power generators.

The main message to scientists is to persevere, to learn the processes that work in educating industry, the community and government. Unless scientists put energy and time into community engagement and education their work may never proceed beyond their laboratories and journals. Integrating fully costed, practical policies into government plans and budgets is part of the democratic deliberations urged to by Kummis.

\subsection{Plans and budgets in government}

It is a challenge to remove the "disconnect" between the annual budget cycle and implementing scientific findings that promise long-term benefits. The public sector agencies responsible for infrastructure have established procedures for linking their long-term strategic plans to short-term funding proposals (e.g. South Australian Strategic Infrastructure Plan) by addressing population, economic indicators, technology and other drivers of infrastructure with a long planning cycle. Environmental planning agencies are beginning to adopt this method. As yet, some strategic plans are more akin to business plans (Queensland Environmental Protection Agency, Strategic Plan 2006-2009). Government can identify the impact of drivers of future environmental degradation, assess their impact and prepare long-term strategic plans to deliver a sustainable environment. These plans identify annual goals that can be funded in the budget. The effects of market failure and inter-generational cost shifting in pricing infrastructure projects both need to be addressed (NZIER [5]). The New South Wales Department of Environment and Conservation stated, "The issues still outstanding are generally more dispersed and diffuse, and less amenable to individual decision-making frameworks. Future solutions will need to be based on a sophisticated integration of regulatory, economic, technological and persuasive approaches" (NSW [6]). This "integration challenge" requires simultaneous attention to, and improvement of, the four challenges of ecological effectiveness, social effectiveness, and eco-efficiency and socio-efficiency" identified by Schaltegger and Burritt ([7]: 192-193). This integration is best achieved through governance frameworks. While governance for sustainability is about working through formal and information institutions (Kemp et al [8]:19), policy integration is not possible if not formalised in national plans and annual budgets. 


\subsubsection{National budget process}

The Government's budget is an annual vehicle that provides authority to spend monies in the coming year and is a formal signal to a country of policy. The ability to obtain parliamentary / national assembly approval for a budget gives government its legitimacy. Each country's "Constitution Act" contains the responsibilities for public finances for both the legislature and Government. The rules of the legislature embody its procedures for considering the budget and financial legislation contains detailed requirements of Governments. Scientists, industry and the community will find it useful to be well versed in the national budget process.

Annual budgets are subject to annual review and short-term criteria. Expenditure with long-term mandates, e.g. pensions, is paid by permanent appropriation, approved outside the annual budget cycle but recorded in the budget papers (Horn [9]: 83-84). All revenue and expenditure is included in the Medium Term Revenue and Expenditure Framework documents.

\subsubsection{Medium Term Frameworks}

The Medium Term Revenue Framework (MTRF), the Medium Term Expenditure Framework (MTEF) and the Medium Term Development Framework (MTDF) contain the current policies, sources of revenue and cost of current and approved policies for more than two cycles of government, i.e. seven or eleven years. The findings of planners, environmentalists, architects and engineers are impotent if they are not incorporated into national plans, MTEF, budget submissions and annual budgets. But MTEFs do not usually include the expenditures of government corporations and statutory bodies, unless they are budget funded.

\subsubsection{Budget submissions}

Individual agencies, including government corporations and statutory bodies, prepare budget submissions and are allocated funding depending on the revenue available, government priorities and their program's / project's contribution to achieving the government's or corporation's goals and objectives.

In all agencies, management is responsible for preparing budgets. If scientists, the community and industry leaders wish to influence this process, and get longterm funding for environmental outcomes, they need to make specific proposals to the Minister and Chief Executive Officers of agencies, and gain the support of managers and the Minister of Finance. Major companies that are now preparing sustainability reports may be allies in encouraging public sector agencies to prepare similar reports. Allies are critical at the outset. When leaders within the community and industry become advocates for the achievement of environmental outcomes, much of a scientist's work is done.

Annual Budget cycles apply to projects designed to achieve environmental outcomes. Integrating ecological, social and economic costs and benefits into the project management cycle is a challenge. It is at the planning stage that scientists can have most influence. But "good ideas" alone will not result in government action. A business case format that incorporates social, ecological and economic costs and benefits needs to be developed. To gain internal departmental support 
for a project, the project manager may prepare a pilot project to establish the viability of a proposal. If the pilot requires more than the use of free staff time, the project manager will assemble a budget proposal. To gain support, the project manager is advised to inform financial staff that the proposal is being prepared and when it will be submitted for inclusion in the department's/ corporation's budget proposal. The Cabinet Budget Committee or Board may look more favourably on the proposal if they are informed of it in the mid-term budget review prior to the budget in which it will be included. Project sponsor and project manager can be expected to work with public sector or other independent scientists to validate costings and benefits. They may also establish inter-governmental support and funding for the project.

The above work is the foundation on which is built political and public sector agency support for an initiative. Without it, requests for funding will not be successful.

\subsubsection{Recognition of costs}

The cost of any budget-funded proposal is weighed against a set of criteria that includes financial and political considerations. Politicians often include intuitive social and ecological criteria in their consideration of financial criteria. But unless these can be measured, there is no means of including them in budgets. The Minister of Finance will be advised on costs. These must meet recognition and measurement requirements of professional accounting bodies. . Public sector budgets determine the transactions to be recorded and reported in financial statements. For example, to be included in a set of accrual financial statements, an item must (1) meet the definition of an element (revenue, expense, asset, liability); (2) be measurable; and (3) be controlled by the entity (IPSAS [10]:2006). To be included in the financial statements, items must be approved in the budget.

The elements of a financial statement apply to a single reporting entity. When a number of public sector agencies collaborate to produce an outcome, such as a reduction in air pollution, the benefit is likely to become a "free good"(i.e. it cannot be controlled by one entity). Sustainability reporting enables the costs and benefits of environmental outcomes to be measured and managed.

\subsection{Applied science's link to a public sector agency budget process}

Individual departmental and corporation budgets are the sources of funding for individual initiatives. Many air pollution initiatives, like other environmental initiatives, require the collaboration of a number of public sector agencies (Health, Transport, Environment, Treasury and the Executive / Cabinet). They also require objectives with a scope wider that for which an individual public sector agency is responsible. For example, there is as yet no budget process for quarantining funds to be spent by a number of agencies in the pursuit of a joint outcome, e.g. air quality. The challenge of collaboration and integration into the policies and budget processes is the responsibility of individual managers.

To achieve environmental outcomes, enhancements to the planning, budgeting and reporting structures are proposed. 


\section{Progress in sustainability reporting}

Governments are beginning to develop plans to address sustainability goals and targets, and to actively report information related to their activities (New Zealand's Programme of Action for Sustainable Development 2003, European Union Energy Initiative). A number of initiatives have encouraged corporations and public sector agencies to publicly report their impact on sustainability. These include the Global Reporting Initiative (GRI)'s Guidelines on Sustainability Reporting (GRI [1]), the International Federation of Accountants (IFAC) "International Guidelines on Environmental Management Accounting" [12], the United Nations Conference on Trade and Development (UNCTAD)'s “Guidance Manual: Accounting and Financial Reporting for Environmental Costs and Liabilities" (UNCTAD [13]). The GRI issued a "Sector Supplement for Public Agencies" in 2005, which stated, "Governments have the mission of enhancing public goods and welfare, and are custodians of national resources and have the right to make and uphold laws, they have an obligation quite different to corporations"(GRI [14]:9). They have "responsibility for their own operations as well as administrative / governing responsibilities in relation to a public policy area or jurisdiction". The supplement identifies three types of information in "triple bottom line / sustainability" reports: (i) organisational performance, (ii) external public policies and implementation measures of the agency that relate to sustainable development and their performance, and (iii) economic, environmental, or social conditions within the agency's mandate or area of jurisdiction. The focus of the GRI framework is on the first and second types of information (GRI 2005:9-10).

The Supplement, in 2005, noted, "sustainability reporting is still in its infancy in the public sector context" (GRI [14]:15). The Centre for Public Agency Sustainability Reporting was established in 2005 to "build capacity in public agencies to undertake sustainability reporting and to facilitate the development of best practice in sustainability reporting" (CPASR [15]). Sustainability reporting by public sector agencies will occur when reports address key national environmental goals that have an eager audience of scientists, community and industry groups and members of the legislature. An eager audience provides agencies with the incentive to develop and implement systems for tracking and reporting sustainability costs and benefits.

But the framework, being born in the private sector, does not yet incorporate public sector accountability conventions that will support its long-term effectiveness. The community, industry, scientists and the legislature need assurance that the information reported is reliable, complete, timely and accurate. It is the Supreme Audit Institution's (SAI) role to provide assurance on formal accountability reports tabled in the legislature. The International Organisation of Supreme Audit Institutions (INTOSAI [16]) has established a Working Group on Environmental Auditing to prepare SAIs to develop environmental auditing tools and techniques. 


\section{Whole-of-government framework}

The public sector sustainability-reporting framework has been designed "to be applied to government and international organisations" (GRI [14]:7). Yet it is not yet being integrated into the core public sector accountability instruments - the budget and financial statements. There are good reasons for this. One is the lack of a budget approval mechanism to apply funds to outcomes achieved by a number of agencies in collaboration with scientists, industry and community bodies. This is further exacerbated when "free goods", such as air, are used by one generation while costs are generated for future generations. Pressure for governments to include ecological and social as well as economic assessment at the strategic planning stage of infrastructure projects improves environmental outcomes. It is at this stage that scientists can best address known risks. For example, the health issues caused by an extended road network.

\subsection{Legislature}

The first step in developing a whole-of-government framework is for legislatures to require public sector agencies to table sustainability reports. The private sector, through individual corporations "Sustainability Reports" in their annual reports, has made substantial progress. The public sector has a more complex challenge. The conditions that led to the voluntary adoption of GRI reporting by private sector corporations do not apply in the public sector where agencies are funded to comply with legislation and achieve policy objectives. Sustainability reports can include the government's / agency's contribution to meeting international or regional environmental goals (e.g. Kyoto goals for reduction in greenhouse emissions). This legislation may need to include the requirement that the SAI has the mandate to do environment audits and to audit sustainability reports.

If sustainability reports are prepared outside the financial governance structure, they are not subject to the same public scrutiny given to budgets and financial statements. The legislature reviews the budget and the government's achievement against its plans recorded in the budget. It has a mandate to investigate issues arising from its review. There will be only occasional legislative and public review of sustainability reports until they are merged into the annual planning and budgeting process, with its consequent reporting in annual reports by individual agencies and whole-of-government financial statements, audited by the SAI.

\subsection{Central agency}

The second step is for central agencies responsible for fiscal and environmental policies to collaborate in the development of budget tools for funding environmental outcomes, to include sustainability goals in budget papers, and to establish a system for reporting sustainability achievements against objectives. They will also need to develop systems for consolidating data from individual 
reports into national reports. Central agencies should monitor the cost of implementation to ensure the benefits are being realised.

\subsection{Public sector agencies}

The third step is for public sector agencies to plan for and report against the achievement of specific sustainability goals. This means they will set up monitoring and evaluation systems to enable the reporting of performance in annual reports.

\subsection{Supreme audit institutions}

The fourth step is for SAIs to develop methodologies for auditing sustainability reports to provide the legislature and the community, industry and the scientific community with assurance on the reports. This may require an extension of their mandate by the legislature.

\section{Conclusion}

With over one thousand corporations world-wide now producing sustainability reports, this type of reporting by public sector agencies is still at a low level. About 50 agencies worldwide are incorporating sustainability reports in their annual reports. Scientists' work requires the political and financial support of the community, industry and government if environmental outcomes are to be achieved. "The vast majority of scientists believe it is their duty to communicate their research and its social and ethical implications to policy makers, and to the non-specialist public" (MORI [3]:4). This paper takes that one step further. Kummis asks scientists to collaborate with the community to incorporate local knowledge in resource management. This paper requests that scientists work with industry, the community and government to build coalitions to achieve goals of improving the environment. Further, it asks them to establish financial and non-financial links between the implementation of their science, and the outcomes that are desired and promised.

This paper has described the government budget process. For an environmental outcome to be achieved it must be included in a budget, short and long-term costs and benefits must meet recognition criteria for inclusion in financial statements. Now that there is a framework in place to report sustainability, public sector agencies can plan and report on environmental costs and benefits and include them in government planning and budgeting. This paper proposed a whole-of-government framework for merging sustainability considerations with government plans and budgets.

\section{References:}

[1] GRI (Global Reporting Initiative) (2006) G3 Reporting Framework, http://www.globalreporting.org/ReportingFramework/G3Online/ 
[2] Kemmis, D. (2006) "Science's Role in Natural Resource Decisions" Issues in Science and Technology, http://www.issues.org/18.4/p_kemmis .htm

[3] MORI (Market and Opinion Research International) (2000) The Role of Scientists in Public Debate, The Wellcome Trust. http://www.wellcome. ac.uk/assets/wtd003425.pdf

[4] van Vuuren, D.P., Cofala, J., Eerens, H.E., Oostenrijk, R., Heyes, C., Klimont, Z., den Elzen, M.G.J. and Amann, M. (2006) "Exploring the ancillary benefits of the Kyoto Protocol for air pollution in Europe" Energy Policy 34, pg 444-460. http://www.mnp.nl/en/publications/2006/ Exploring the ancillary_benefits_of_the_Kyoto_Protocol_for_air_polluti on_in_Europe.html

[5] NZIER (New Zealand Institute of Economic Research (2004) "Sustainable infrastructure: A Policy Framework" Report to the Ministry of Economic Development May. http://www.med.govt.nz/templates/ MultipageDocumentTOC 9191.aspx

[6] NSW (New South Wales) (2006) Future Directions, State of the Environment,

http://www.environment.nsw.gov.au/soe/soe2006/chapter1/chp_1.1.htm\#1 .1 .5

[7] Schaltegger, S. and R.L. Burritt $(2005 / 6)^{\circ}$ Corporate Sustainability' chapter in Tietenberg, T. and Folmer, H. (Eds) The International Yearbook of Environmental and Resource Economics 2005/2006 Edward Elgar Publishing, Northampton, Mass. Vol.8, (2005) pp.185-222.

[8] Kemp, R., Parto, S. and Gibson, R.B. (2005) 'Governance for sustainable development: moving from theory to practice', Int. J. Sustainable Development, Vol 8, Nos. 1/2, pp.12-30.

[9] Horn, M. (1995) "The Political Economy of Public Administration" Cambridge, UK, Cambridge University Press, pp. 83-84.

[10] IPSAS 6 (2006) Consolidated Financial Statements and Accounting for Controlled Entities, International Public Sector Accounting Standards, See: http://www.ifac.org/PublicSector/

[11] Ministry for the Environment (2003) Sustainable Development for New Zealand, Programme of Action, http://www.mfe.govt.nz/publications/sus$\operatorname{dev} /$

[12] IFAC (2005) International Guidance Document: Environmental Management Accounting International Federation of Accountants, www.ifac.org

[13] UNCTAD (United Nations Conference on Trade and Development) (2002), "Guidance Manual: Accounting and Financial Reporting for Environmental Costs and Liabilities" Geneva. http://www.greenbiz.com/ frame/1.cfm?targetsite=http://www.unctad.org/en/subsites/dite/3_edev/3_i sarm.htm

[14] GRI (2005) "Sector Supplement for Public Agencies Pilot Version 1.0 With an abridged version of the FRI 2002 Sustainability Reporting Guidelines March, Global Reporting Initiative, Netherlands. 
[15] Centre for Public Agency Sustainability Reporting (2007) Website at http://www.publicagencyreporting.org/, last accessed January 2007.

[16] INTOSAI (International Association of Supreme Audit Institutions) (2007) Website of Working Group on Environmental Auditing. http://www.environmental-

auditing.org/intosai/wgea.nsf/viewHTML/mission.htm!OpenDocument\&n av $=$ mission

[17] GRI (Global Reporting Initiative) (2004) "Public Agency Sustainability Reporting: A GRI Resource Document in Support of the Public Agency Sector Supplement Project", UNEP, p.8.

[18] UNDSD (United Nations Division for Sustainable Development) (2001), "Environmental Management Accounting: Policies and Linkages" New York.

[19] UNDSD (2001) “Environmental Management Accounting: Procedures and Principles" New York.

[20] Auditor-General (2005) Auditor-General's Performance Audit "Managing Air Quality: Department of Environment and Conservation", NSW Parliament.

http://www.audit.nsw.gov.au/publications/reports/performance/2005/air_q uality/Airquality-contents.html

[21] Williams, M. (2006) "Pushing the Limits too Far" Sustainability forum Issue 1, http://www.pce.govt.nz/projects/topic1.shtml).

[22] GRI (Global Reporting Initiative) (2004), Public Agency Sustainability Reporting: A GRI Resource Document in Support of the Public Agency Sector Supplement Project, pages 3-4, and 22. http:/www.globalreporting.org/NR/rdonlyres/69CB7A1F-60FF-4804A29E-EC19AB9C2AB7/0/ResearchProjectPublicAgecny.pdf 